\section{After one year}

\section{Sergio J. Ochatt}

Morphogenèse et Validation, Centre de Recherches INRA de Dijon, France

It is now one full year since the first manuscript submitted to the International Journal of Plant Biology was published online. Proof of the good health of our journal, 18 papers have already been published online in 2010 (volume 1 , issues $\mathrm{n}^{\circ} 1$ and 2 ) and there are presently 17 under review and 2 already in editing. Moreover, the site of the International Journal of Plant Biology has been accessed nearly 13,000 times in 2010 and not far from 6,000 times in the first four months of 2011, as shown below. In other words, about 19,000 of the published papers have been successfully downloaded from the site either as pdf or html files. We constantly strive to increase our efforts and encourage researchers and scientists to consider submitting their manuscripts to the journal. The scientific quality of the manuscripts submitted is in continuous increase and this has had an impact on the number of submissions that could not be accepted, or where authors were required to undertake significant modifications before they were. This will in time contribute to increasing the perception of the journal's content and we hope to obtain our first Impact Factor figures in the coming future.

With the increase in the world's population and need for food, the understanding of Plant Biology as a means of improving yields whilst contributing to a sustainable agriculture is the

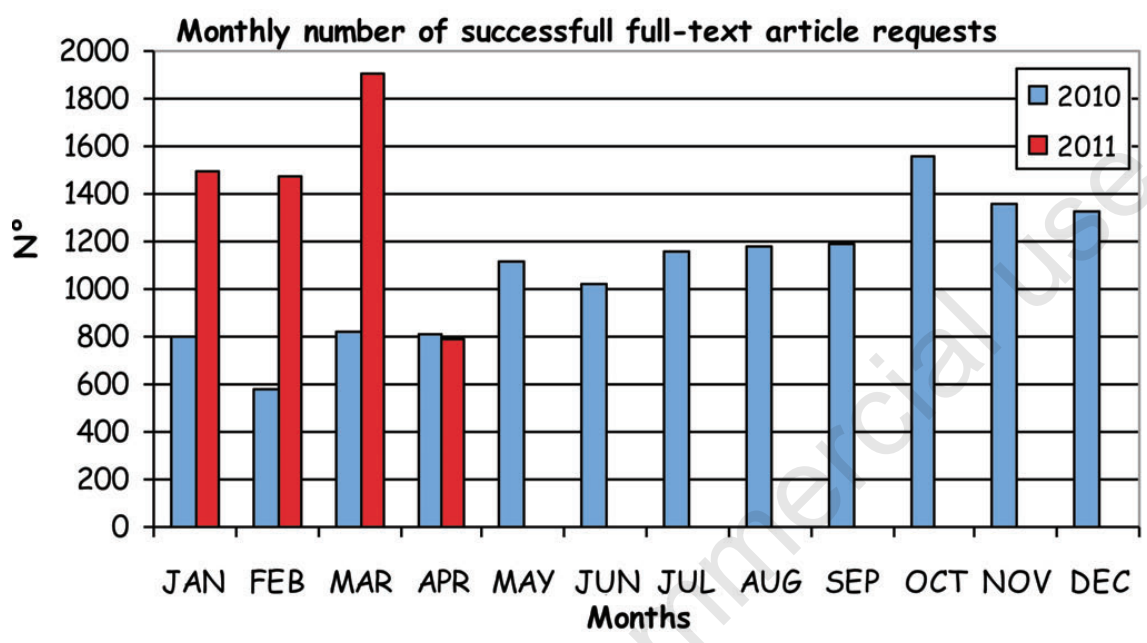

Correspondence: Sergio J. Ochatt,

Morphogenèse et Validation, Centre de Recherches INRA de Dijon, France.

E-mail: sergio.ochatt@dijon.inra.fr

This work is licensed under a Creative Commons Attribution 3.0 License (by-nc 3.0).

(C) Copyright S.J. Ochatt, 2011

Licensee PAGEPress, Italy

International Journal of Plant Biology 2011; 2:e3 doi:10.4081/pb.2011.e3

object of a large international interest. The different areas covered by the International Journal of Plant Biology are in line with the global scientific work and highlight even more the importance of the field, by providing researchers with the opportunity to publish their results and make them accessible to everybody online.

Now that we are one-year-old, it is a suitable time to thank all of the contributors. Special thanks are due to the associate editors and referees, without whose personal investment and scientific expertise this would have been impossible. I would like to express my most sincere and wholehearted thanks to Nicole Pezzolo, who as peer-review manager has been instrumental for the journal's success to date. Cristiana Poggi and Filippo Lossani have skilfully assured the production management and technical support, respectively.

Finally, I would like to encourage you to continue submitting your research results to the International Journal of Plant Biology. 